\title{
GENERALIZED QUASILINEARIZATION METHOD FOR A FORCED DUFFING EQUATION WITH THREE-POINT NONLINEAR BOUNDARY CONDITIONS
}

\author{
BASHIR AHMAD, AHMED Alsaedi AND BADRA Alghamdi
}

Abstract. We develop a generalized quasilinearization method for a forced Duffing equation with three-point nonlinear boundary conditions and obtain two monotone sequences of approximate solutions converging quadratically to the unique solution of the problem.

Mathematics subject classification (2000): 34A37, 34B15.

Key words and phrases: Quasilinearization, Duffing equation, quadratic convergence.

\section{REFERENCES}

[1] R. Bellman, Methods of Nonlinear Analysis, Vol. 2, Academic Press, New York, 1973.

[2] R. Bellman and R. Kalaba, Quasilinearization and Nonlinear Boundary Value Problems, Amer. Elsevier, New York, 1965.

[3] E. S. LEE, Quasilinearization and Invariant Embedding, Academic Press, New York, 1968.

[4] V. LAKSHMiKantham, An extension of the method of quasilinearization, J. Optim. Theory Appl. 82 (1994), 315-321.

[5] V. LaKSHMiKANTHAM, Further improvement of generalized quasilinearization, Nonlinear Anal. 27 (1996), 223-227.

[6] B. AHMAD, A quasilinearization method for a class of integro-differential equations with mixed nonlinearities, Nonlinear Anal.: Real World Appl. 7 (2006), 997-1004.

[7] B. AHMAD, R. A. KHAN AND S. SivASUNDARAM, Generalized quasilinearization method for a first order differential equation with integral boundary condition, Dynam. Contin. Discrete Impuls. Systems Ser. A Math. Anal. 12 (2005), 289-296.

[8] B. Ahmad, A. Al-SAedi AND S. Sivasundaram, Approximation of the solution of nonlinear second order integro-differential equations, Dynamic Systems Appl. 14 (2005), 253-263.

[9] R. A. KHAN AND R. RODRIGUEZ-LOPEZ, Existence and approximation of solutions of second order nonlinear four point boundary value problems, Nonlinear Anal. 63 (2005), 1094-1115.

[10] V. LaKShMikANTHAm AND A. S. VATSAla, Generalized quasilinearization versus Newton's method, Appl. Math. Comput. 164 (2005), 523-530.

[11] F. M. ATICI AND S. G. TOPAL, The generalized quasilinearization method and three-point boundary value problems on time scales, Appl. Math. Lett. 18 (2005), 577-585.

[12] A. BUICA, Quasilinearization method for nonlinear elliptic boundary value problems, J. Optim. Theory Appl. 124 (2005), 323-338.

[13] A. R. ABD-Ellateef KAMAR AND Z. DRICI, Generalized quasilinearization method for systems of nonlinear differential equations with periodic boundary conditions, Dynam. Contin. Discrete Impuls. Systems Ser. A Math. Anal. 12 (2005), 77-85.

[14] T. JANKOWSKI, Quadratic approximation of solutions for differential equations with nonlinear boundary conditions, Compu. Math. Appl. 47 (2004), 1619-1626.

[15] P. ElOE AND Y. GAO, The method of quasilinearization and a three-point boundary value problem, J. Korean Math. Soc. 39 (2002), 319-330. 
[16] B. AHMAD, J. J. NIETO AND N. SHAHZAD, The Bellman-Kalaba-Lakshamikantham quasilinearization method for Neumann problems, J. Math. Anal. Appl. 257 (2001), 356-363.

[17] A. CABADA AND J. J. NIETO, Quasilinearization and rate of convergence for higher order nonlinear periodic boundary value problems, J. Optim. Theory Appl. 108 (2001), 97-107.

[18] S. Nikolov, S. Stoytchev, A. Torres AND J. J. NiETO, Biomathematical modeling and analysis of blood flow in an intracranial aneurysms, Neurological Research 25 (2003), 497-504.

[19] J. J. NIETO AND A. TORRES, A nonlinear biomathematical model for the study of intracranial aneurysms, J. Neurological Science 177 (2000), 18-23.

[20] V. Lakshmikantham and A. S. Vatsala, Generalized Quasilinearization for Nonlinear Problems, Kluwer Academic Publishers, Dordrecht, 1998.

[21] I. YERMACHENKO AND F. SADYRBAEV, Quasilinearization and multiple solutions of the Emden-Fowler type equation, Math. Model. Anal. 10 (2005), 41-50.

[22] V. B. MANDELZWEIG AND F. TABAKIN, Quasilinearization approach to nonlinear problems in physics with application to nonlinear ODEs, Computer Physics Comm. 141 (2001), 268-281.

[23] W. CopPel, Disconjugacy, Lecture Notes in Mathematics, Vol. 220, Springer-Verlag, NewYork/Berlin (1971).

[24] I. T. KigURADZE AND A. G. LOMTATIDZE, On certain boundary value problems for second-order linear ordinary differential equations with singularities, J. Math. Anal. Appl. 101 (1984), 325-347.

[25] C. P. GUPTA, A second order $m$-point boundary value problem at resonance, Nonlinear Anal. 24 (1995), $1483-1489$.

[26] C. P. GUPTA AND S. TROFIMCHUCK, A priori estimates for the existence of a solution for a multi-point boundary value problem, J. Inequal. Appl. 5 (2000), 351-365.

[27] J. J. NIETO, Generalized quasilinearization method for a second order differential equation with Dirichlet boundary conditions, Proc. Amer. Math. Soc. 125 (1997), 2599-2604.

[28] A. CABADA, J. J. NIETO AND RAFAEL PITA-DA-VEIGE, A note on rapid convergence of approximate solutions for an ordinary Dirichlet problem, Dynam. Contin. Discrete Impuls. Systems 4 (1998), 23-30.

[29] B. AHMAD AND H. HUDA, Generalized quasilinearization method for nonlinear nonhomogeneous Dirichlet boundary value problems, Int. J. Math. Game Theory Algebra 12 (2002), 461-467.

[30] L. JACKSON, Boundary value problems for ordinarydifferential equations (Studies in Ordinary Differential Equations, Ed. J. K. Hale), MAA Studies in Mathematics, Mathematical Association of America, 14 (1977), 93-127. 